\title{
Twins, Chorionicity and Zygosity
}

\author{
Robert Derom', Elizabeth Bryan², Catherine Derom', Louis Keith³, and Robert Vlietinck' \\ ' Centre for Human Genetics, Katholieke Universiteit Leuven, Leuven, Belgium \\ ${ }^{2}$ Multiple Births Foundation, London, UK \\ ${ }^{3}$ Northwestern University Medical School and The Center for the Study of Multiple Birth, Chicago, Illinois \\ Aided by grants number 3.0038.82 and 3.0008.90 of the Fund for Medical Scientific Research (Belgium)
}

\begin{abstract}
ccurate determination of zygosity and chorionicity is essential $A$ in all multiple maternities. The parents and the multiples themselves ask it. It is of medical importance and now considered as a prerequisite in several domains of twin research, especially when perinatal data are analysed. It helps the multiples and their parents and teachers to ascertain identity. The methods are briefly described and a plea is made to obstetricians and paediatricians to use them systematically at the time of birth.
\end{abstract}

It was during the first meeting of the ISTS Working Group on Multiple Pregnancy, held in Aberdeen in April 1979, that my wife and I had the opportunity to truly appreciate Ian and Edith MacGillivray. Our friendship has lasted ever since and has been one of the highlights of my ISTS membership. Among the numerous scientific merits of Ian, one stands out in particular. Ian was, as far as we know, the first to establish an optimal population-based twin registry in which all essential obstetric data - especially of placentation - were included. Subsequently, the East Flanders Prospective Twin Survey (EFPTS) was established according to the Aberdeen model. However, Ian is THE true pioneer in one of the most important methodological domain of twin research.

More and more didymologists $(\delta \imath \delta v \mu o \sigma=$ twin $)$ are convinced that the determination of zygosity and chorionicity is a must in twin research. The community of multiples and their parents join them in the desire for this knowledge. They are aware of the importance of investigations that are so near to their personality and their relationship to the other member(s) of the set. Accordingly, The Council of Multiple Birth Organisation(COMBO) of the International Society for Twin Studies (ISTS) has adopted, in 1996, the Declaration of Rights and Statement of Needs of Twins and Higher Order Multiples (The Council of Multiple Birth Organisation, 1998):

Whereas the zygosity of same-sex multiples cannot be reliably determined by their appearance; and whereas 1) the heritability of dizygotic (two-egg) twinning increases the rate of conception of multiples; 2) the similar biology and inheritance of monozygotic (one-egg) multiples profoundly affect similarities in their development; 3) monozygotic multiples are blood and organ donors of choice for their co-multiples; and 4) the availability of the placenta and optimal conditions for determining zygosity are present at birth:
- Parents have a right to expect accurate recording of placentation and the diagnosis of the zygosity of samesex multiples at birth.

- Older, same sex multiples of undetermined zygosity have a right to testing to ascertain their zygosity.

With this declaration in mind, we will summarise the reasons why it is essential to determine the zygosity of multiple births and stress the importance of doing this at birth and including placentation in the process.

\section{Why Determine Zygosity at Birth}

The three important reasons to determine zygosity at birth are (1) medical; (2) scientific and (3) personal.

\section{Medical Aspects}

Zygosity is of particular importance in questions of organ transplantation and inheritance of specific disease states. Because of the high perinatal mortality in multiple births, one should resort to proper investigations as soon as the infants are born. If one or more new-borns of a set of twins or triplets die in the first days of life and anomalies are later found in the surviving member of the set, the possibility to determine zygosity may be lost forever. Errors in diagnosis can have important medical consequences (St. Clair et al., 1998).

\section{Scientific Research}

Scientifically, the study of multiple births has a long and illustrious history. An entire generation of modern investigators have laboured to determine the relative contribution of genetics and the environment to the human state. In these studies, they have generally used comparisons between monozygotic (MZ) and polyzygotic (PZ) twins, triplets, quadruplets, etc., and singletons. Much more could be learned by a twin-pronged attack on complex traits (Martin et al., 1997).

\section{Identity and Education}

The question of zygosity has a special importance to twins, triplets, etc. and their families at home, in the school and in the place of work. Each person should be able to identify

Address: Association for Scientific Research in Multiple Births, Kwadenplasstraat 12, B-9070 Destelbergen (Belgium): email : r.derom@belgacom.net 
himself in order to distinguish himself from his surrounding. Considering the educational process, it is essential that the twins, triplets, etc., and their teachers should be correctly informed. It is only natural for parents to want to learn all they can about their babies and with twins this includes zygosity and chorionicity. Later the twins themselves are usually keen to know. The reasons given by parents for wanting to know the zygosity include:

- for their own interest

- to avoid embarrassment when asked the most common question, "are they identical?"

- to understand the significance of similarity or different rates of growth and psychomotor development

- to reinforce their resolve to treat them as individuals if they are identical

- to assess the risks of having twins again (increased for women who have nonidentical twins).

The twins and the higher other multiples themselves also are keen to be certain about their zygosity. Repeatedly, and more and more as the years go by, multiples are also anxious for a scientifically based diagnosis. Given these circumstances, we as obstetricians must not fail our patients and their children with a "laissez faire" attitude. We must set in place programs to insure that zygosity is indeed determined at birth, regardless of other factors (Derom et al., 1991).

\section{$\overline{\text { Methods of Zygosity Determination at Birth }}$}

Two of these, differences in sex and blood groups, are well known and do not need to be discussed here. We shall therefore deal with two aspects: the anatomy of the fetal membranes and the determinations of placental DNA.

\section{Fetal Membranes}

Careful examination of these membranes enables to diagnose two thirds of the monozygotic twin pairs themselves or pairs that are part of sets of higher order multiple births. It is axiomatic that monochorionicity means monozygosity. Whereas in twins the number of types of membrane structure is limited to three - dichorionic, monochorionic-monoamnionic and monochorionicdiamnionic - in higher order multiple births this number increases substantially. Specifically, six combinations are encountered in triplets. Theoretically, as many as 10 types are possible in quadruplets and 15 in quintuplets. Practically speaking, some of these last mentioned types are seldom if ever encountered. What is important in all instances is to number the chorionic membranes (Derom et al., 1995).

The best way to proceed is to reconstruct, as it where, the different sacs and to dissect the dividing membranes after removing part for histological examination (histology may be skipped when one has acquired sufficient experience). If, after removal of the amnionic membranes on both sides of the dividing membranes, a layer of tissue remains, then these sacs are separated by chorionic tissue. Proceed in the same fashion to the next dividing membrane until all sacs have been stripped of amnion (if two sacs are separated by amnion only they will have been reduced to a single cavity). Count the number of sacs which equals the number of chorionic membranes (chorionic membranes of adjoining sacs are generally fused and cannot be separated by blunt dissection). Although careful examination of the fetal membranes gives unequivocal results as far as diagnosis of monozygosity in concerned, it is our experience (Derom et al., unpublished data) and that of others (Potter, 1963; Potter \& Fuller, 1949; Rydhström, 1999) that only properly trained personnel, who are investigating more than an occasional case, can be trusted.

Chorionicity is not only useful for zygosity diagnosis but it is also essential for subdividing the monozygotic pairs according to the time of division of the zygote. It is now established what the time intervals are (Chitnis et al., 1999; Monteiro et al., 1998) and the specific impacts the placental anatomy has on fetal life. Birthweight is higher and within-pair birthweight differences are lower after early division, clearly the optimal condition (Derom et al., 1995). After intermediate and late division, on the other hand, placental vascular anastomoses are almost always present, leading to hemodynamic imbalance in a significant, albeit unknown, number of cases. In late division the sex proportion is definitely moved to the female side (75\%; Derom et al., 1995).

Where facilities are available chorionicity may be detected by ultrasound early in pregnancy. According to Fisk and Bryan (1993) it should be done routinely as it is relevant to

- counselling regarding to the risk of perinatal morbidity and mortality (monochorionic twins have a five times higher rate of late miscarriage and perinatal mortality than DC twins)

- counselling regarding the risk of genetic and structural abnormality

- invasive testing and management of discordant abnormality

- feasibility of feticide or MFPR when appropriate

- risk of sequelae in the presence of fetal compromise

- early detection and management of complications of MC twins.

\section{Placental DNA: A New Dimension}

Since 1980, introduction of the "new genetics" allows researchers to bypass the determination of genetic markers and to read the genetic code itself. DNA analysis has been used in EFPTS since 1982 on more than 500 twin pairs and 100 sets of triplets. The placenta contains large quantities of fetal DNA. Its extraction and purification does not present much difficulty. Using six polymorphic probes, the effectiveness of zygosity diagnosis increased to a level, which can only be reached by investigating 8 or more blood group systems (Derom et al., 1985). Even better results can now be obtained with the highly polymorphic minisatellite probes, popularly called DNA fingerprinting. DNA analysis has another major advantage; that is, it allows determination of the genotype of infants who are stillborn 
and macerated, something that is generally not possible with other methods (Derom et al., 1991).

The advantages of DNA analysis can be summarised in 5 points:

(1) placental tissue, rich in DNA, can be stored for long periods of time in the regular freezer $\left(-20^{\circ} \mathrm{C}\right)$

(2) theoretically the number of polymorphism's is unlimited

(3) in cases of fetal death with maceration, typing of samples of placental tissue is still possible

(4) DNA can be extracted from a variety of tissues (blood, buccal mucosa, etc.)

(5) because DNA is easy to extract, this analysis can be applied when the twins are investigated to localise genes by the sib method.

DNA analysis is too elaborate and probably too expensive to be applied on a large scale. One should, therefore, exhaust all conventional methods before turning to what is known as the new genetics. The rational use of the tools which are now available is described elsewhere (Vlietinck, 1986). It contains a flow diagram on the optimal procedure to reach a differential diagnosis which is as accurate as possible. One may question the cost-benefit ratio of this examination, but one should consider the following: Today it costs USD 200 for one determination. It is a safe bet to suggest that within the coming years these costs will drop substantially. Such costs are negligible additions to total expenditures for multiple deliveries in industrialised (OESO) countries and are balanced by the prospect of livelong personal, scientific and medical benefits.

\section{Conclusion}

Again we call upon the obstetrician and the neonatologist: $\mathrm{He} /$ she must demand accurate chorionicity and zygosity determination in all twin and higher order multiple births, be they spontaneous or induced. It is his or her responsibility to do this at the proper time, i.e. at birth, by the proper methods, the essential step being the investigation of the placenta.

\section{References}

Chitnis, S., Derom, C., Vlietinck, R., Derom, R., Monteiro, J., \& Gregersen, P. K. (1999). X -chromosome-inactivation patterns confirm the late timing of monoamniotic-MZ twinning. American Journal of Human Genetics, 65, 570-571.

Council of Multiple Birth Organisations (COMBO). (1998). Declaration of rights and statement of needs of twins and higher order multiple births. Twin Research, 1, 52-56.

Derom, C., Bakker, E., Vlietinck, R., Derom, R., Van Den Berghe, H., Thiery, M., \& Pearson, P. (1985). Zygosity determination in newborn twins using DNA variants. Journal of Medical Genetics, 22, 279-282.

Derom, C., Vlietinck, R. F., Derom, R., Boklage, C., Thiery, M., \& Van Den Berghe, H. (1991). Genotyping macerated stillborn fetuses. American Journal of Obstetrics \& Gynecology, 164(3), 797-800.

Derom, R., Derom, C., \& Vlietinck, R. (1995). Placentation. In L. G. Keith, E. Papiernik, Keith, D. M., \& Luke, B. (Eds), Multiple pregnancy: Epidemiology, gestation \& perinatal outcome (pp. 113-128). New York: Parthenon.

Derom, R., Vlietinck, R., Derom, C., Keith, L. C., \& Van Den Berghe, H. (1991). Zygosity determination at birth: a plea to the obstetrician. Journal of Perinatal Medicine, 19(1), 234-404.

Fisk, N. M., \& Bryan, E. (1993). Routine prenatal determination of chorionicity in multiple gestation: A plea to the obstetrician. British Journal of Obstetrics and Gynaecology, 100, 975-977.

Martin, N., Boomsma, D., \& Machin, G. (1997). A twin-pronged attack on complex traits. Nature Genetics, 17, 387-392.

Monteiro, J., Derom, C., Vlietinck, R., Kohn, N., Lesser, M., $\&$ Gregersen, P. K. (1998). Commitment to X inactivation precedes the twinning event in monochorionic MZ twins. American Journal of Human Genetics, 63, 339-346.

Potter, E. L. (1963). Twin zygosity and placental form in relation to the outcome of pregnancy. American Journal of Obstetrics \& Gynecology, 97, 566-577.

Potter, E. L., \& Fuller, H. (1949). Multiple pregnancies at the Chicago lying-in Hospital 1941-1947. American Journal of Obstetrics \& Gynecology, 58, 139-149.

Rydhström, H. (1998). Medicinsk sensation eller dalig registering (Swedish). Jordemodern, 3, 90.

St. Clair, D. M., St Clair, J. B., Swainson, C. P., Bamforth, F., \& Machin, G. A. (1998). Twin zygosity testing for medical purposes. American Journal of Medical Genetics, 77, 412-414.

Vlietinck, R. F. (1986). Determination of the zygosity of twins. Unpublished doctoral dissertation, Katholieke Universiteit Leuven. 